\title{
Diamination of Conjugated Dienes and Trienes Catalyzed by $N$-Heterocyclic Carbene-Pd(0) Complexes
}

\author{
Liang Xu, Haifeng Du, and Yian Shi* \\ Department of Chemistry \\ Colorado State University \\ Fort Collins, CO 80523 \\ Phone: 970-491-7424 \\ Fax: 970-491-1801 \\ Email: yian@lamar.colostate.edu
}

\section{Supporting Information}

\section{Table of Contents}

NMR spectra of diamination product

S-2 


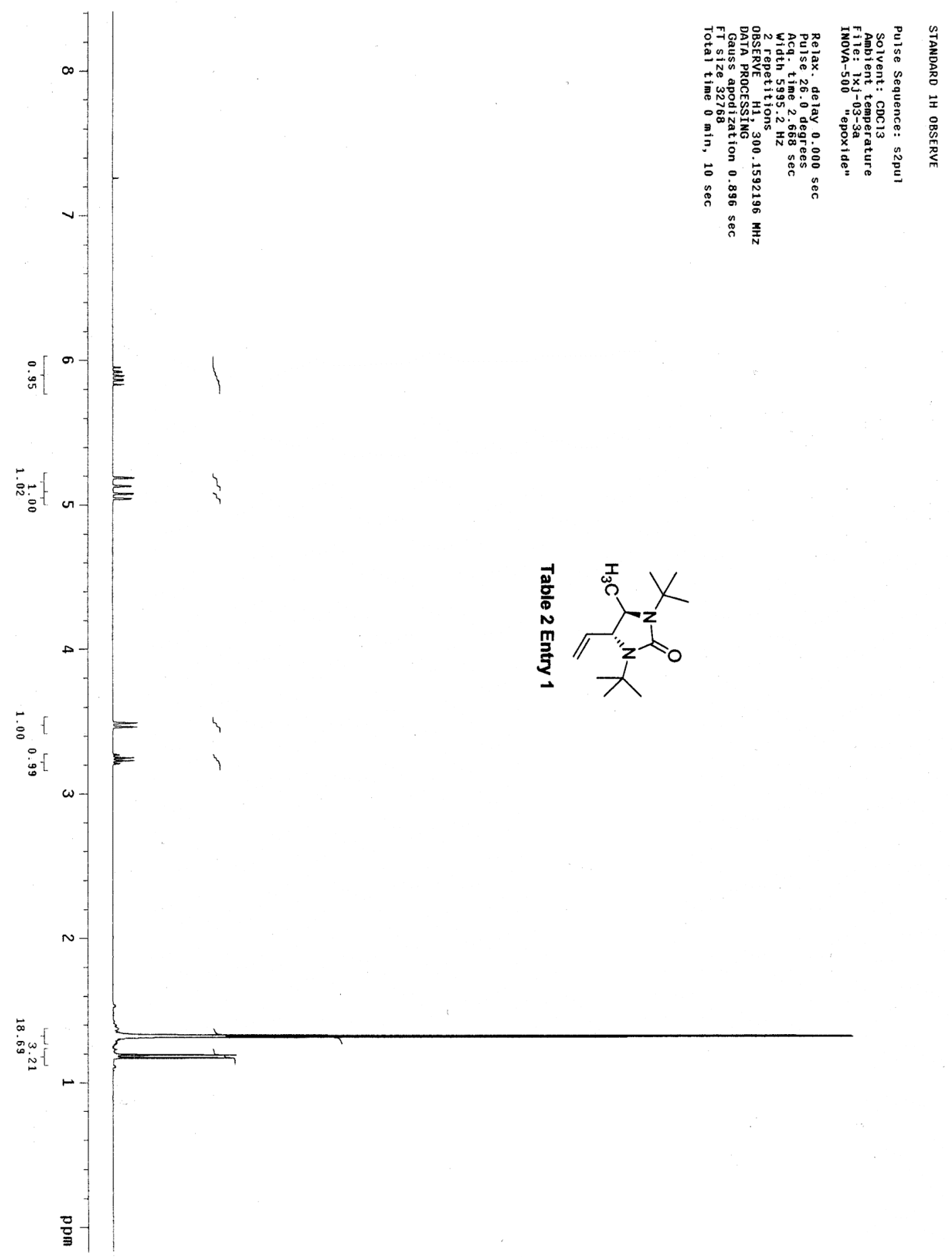




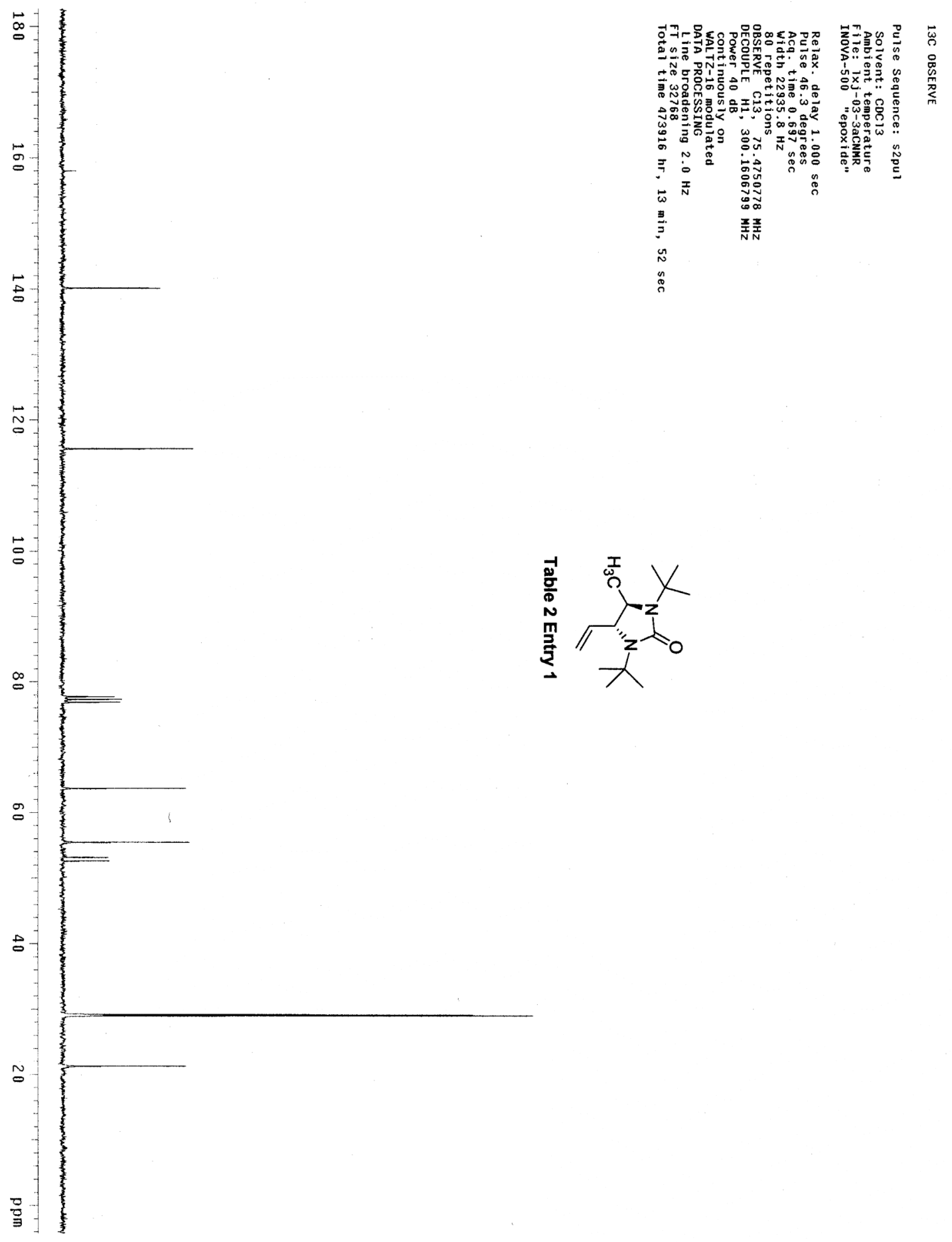

S-3 


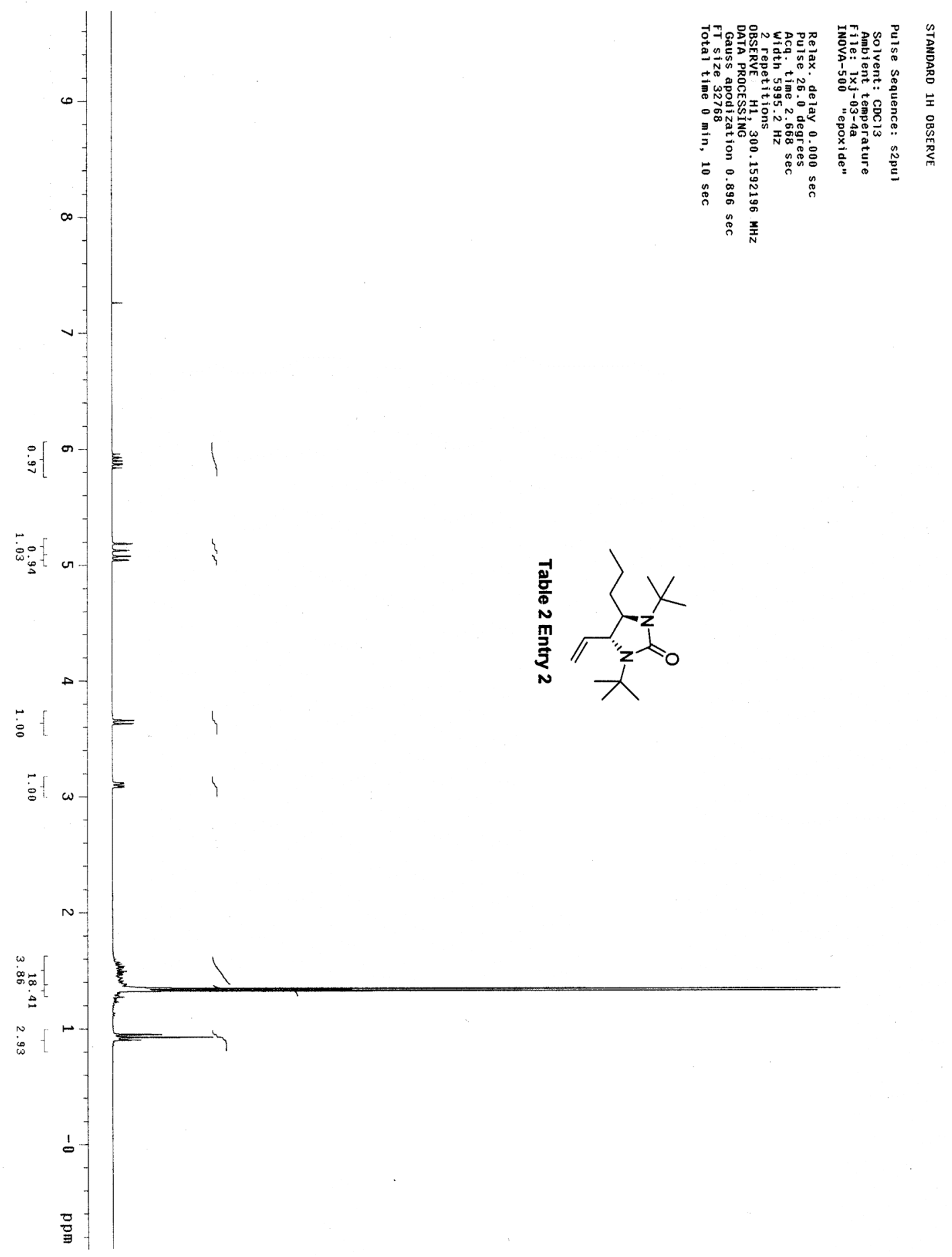



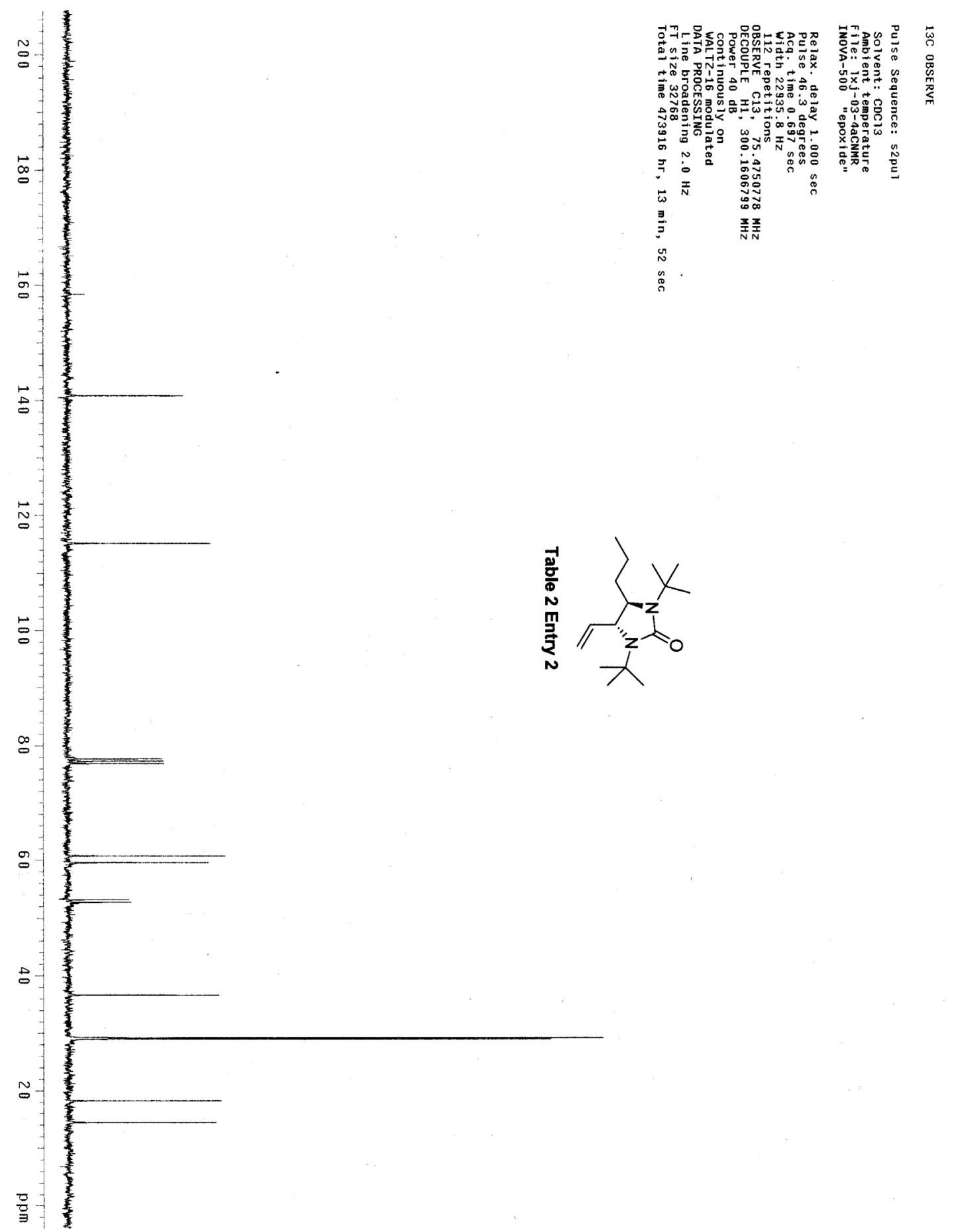


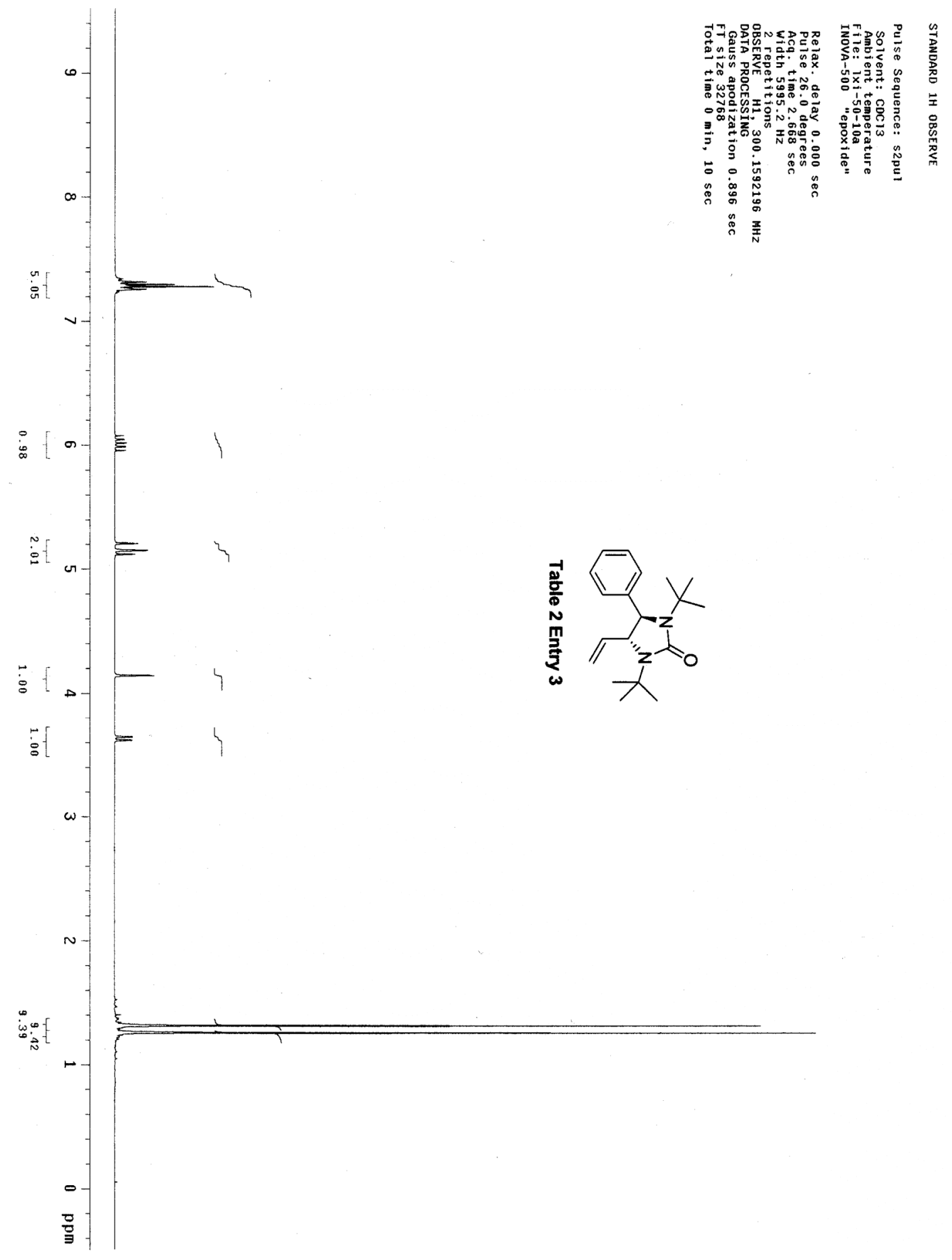



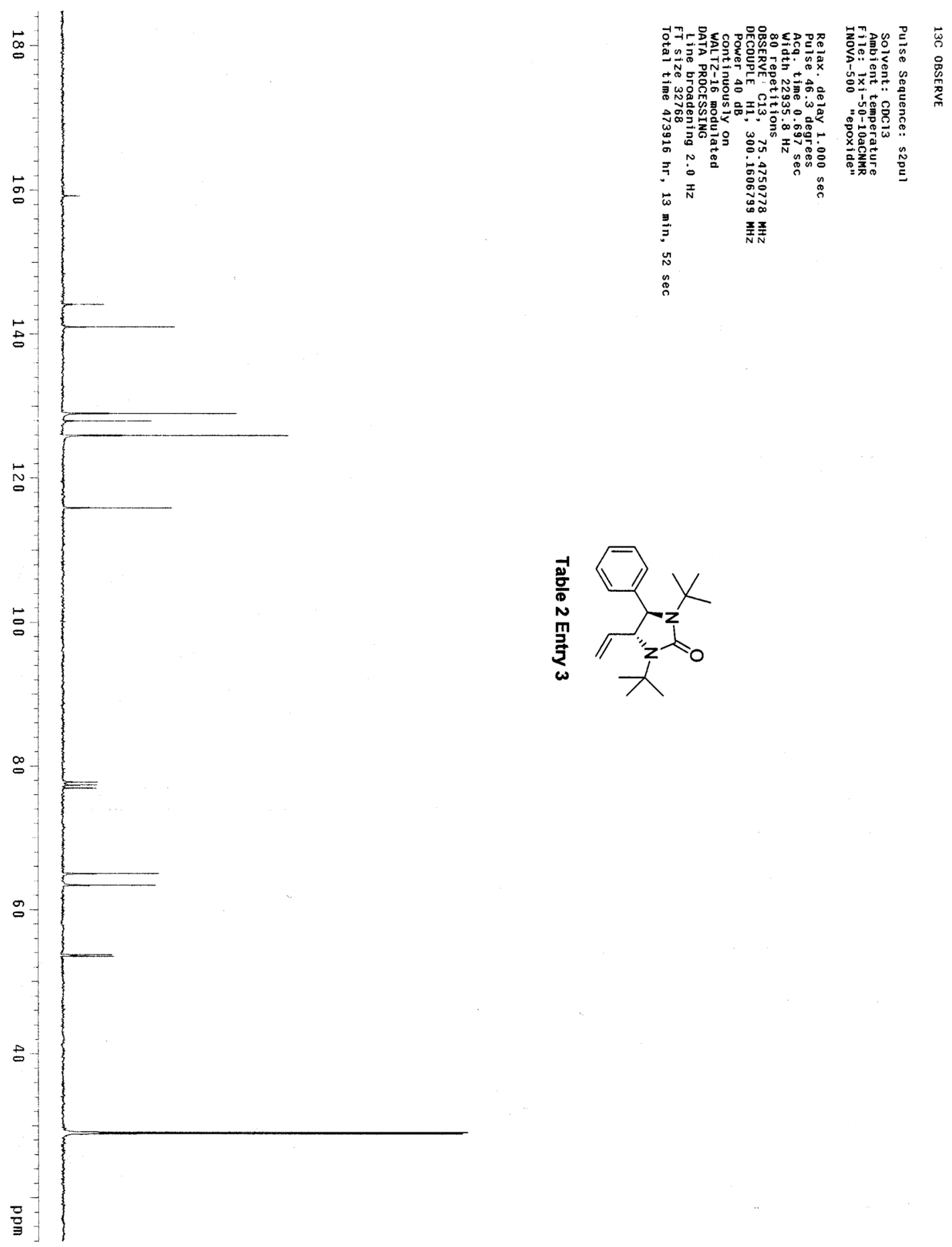

S-7 


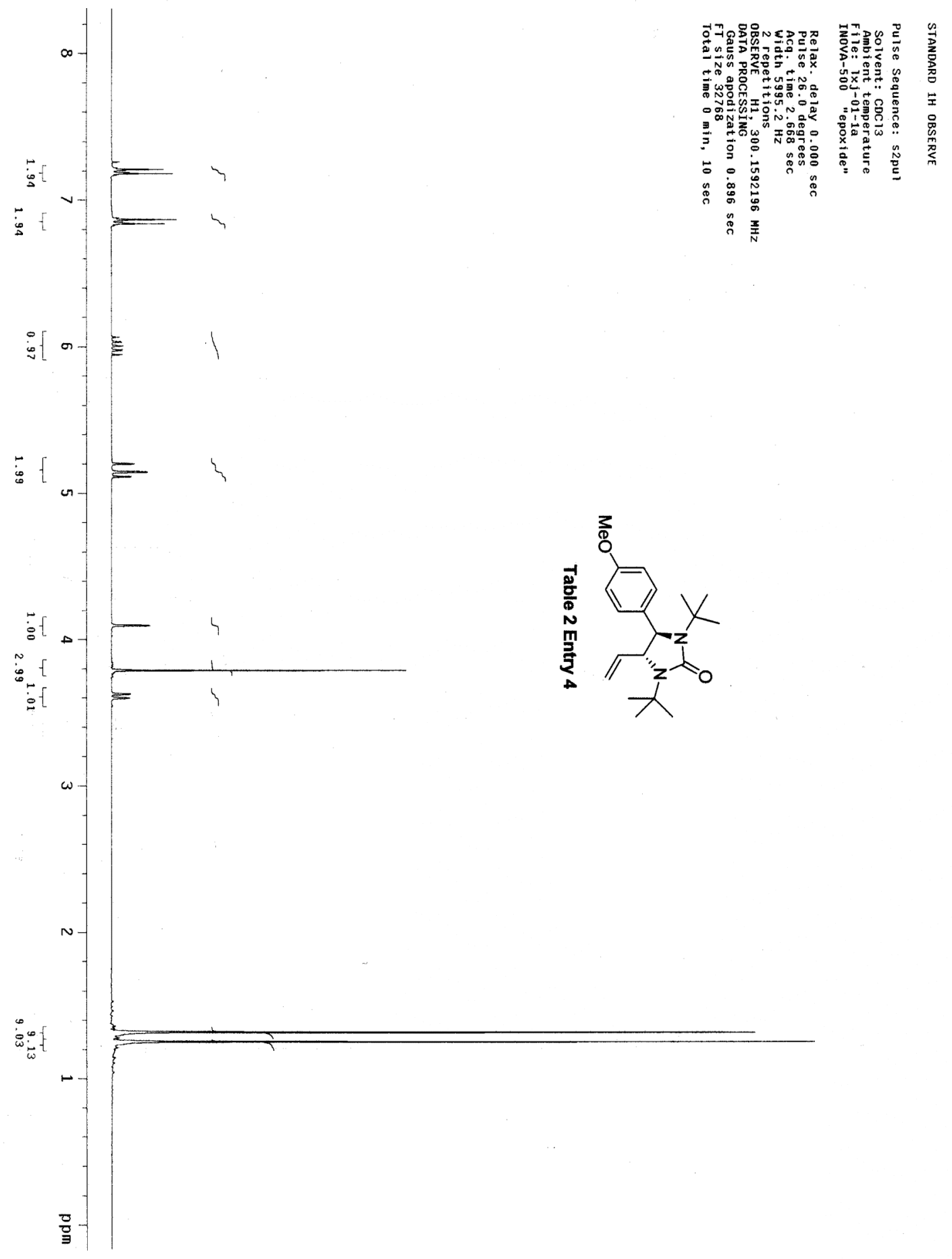



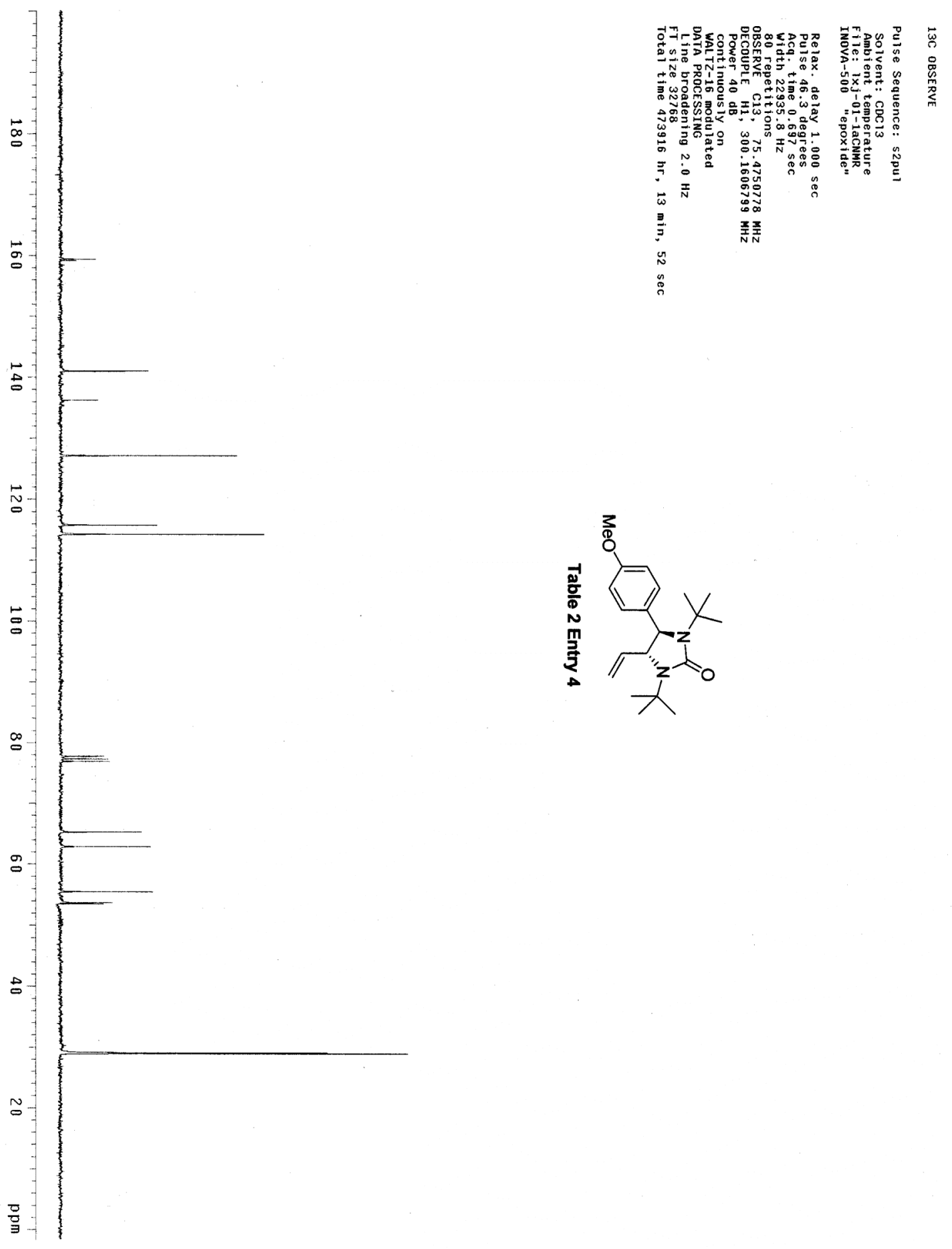


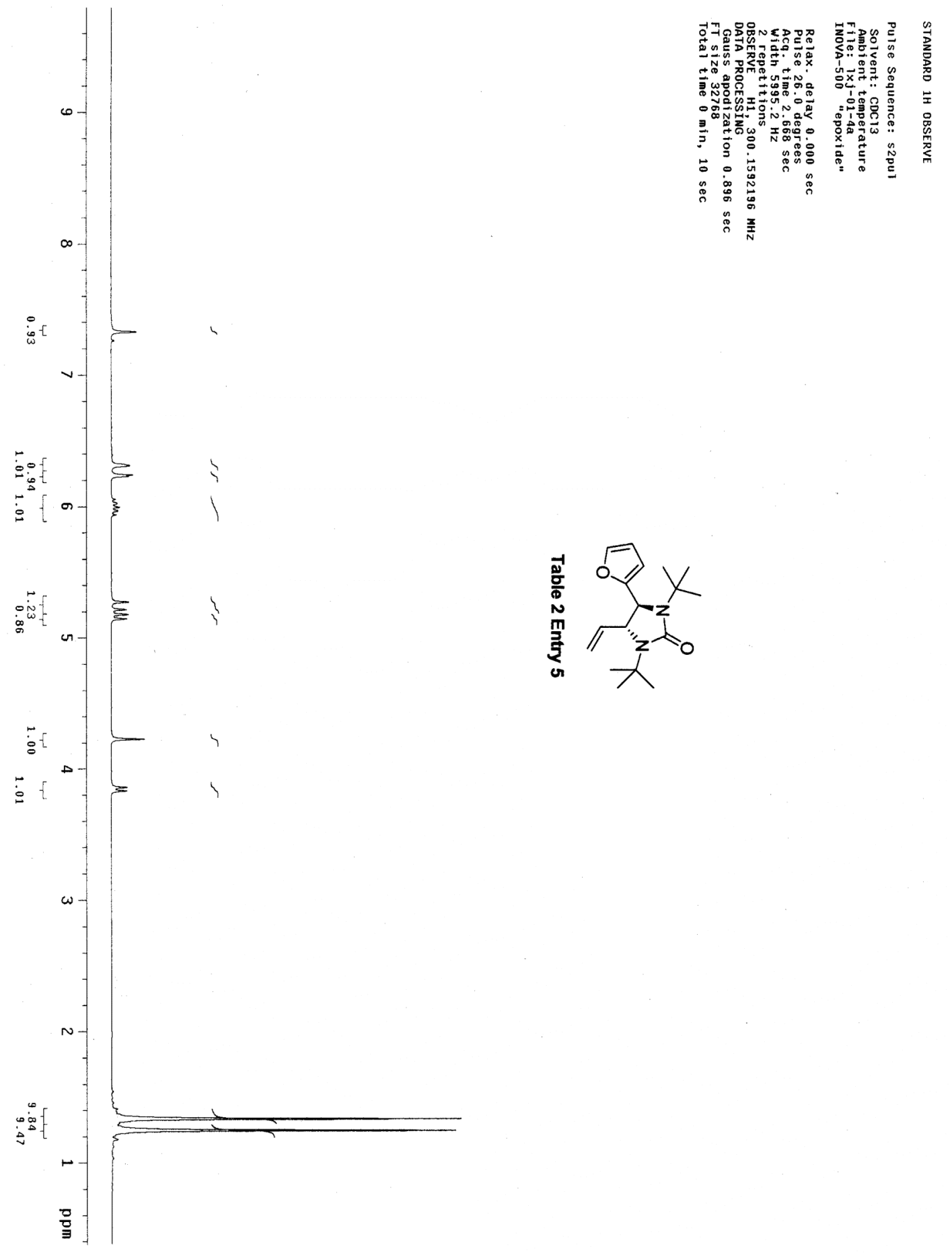

S-10 

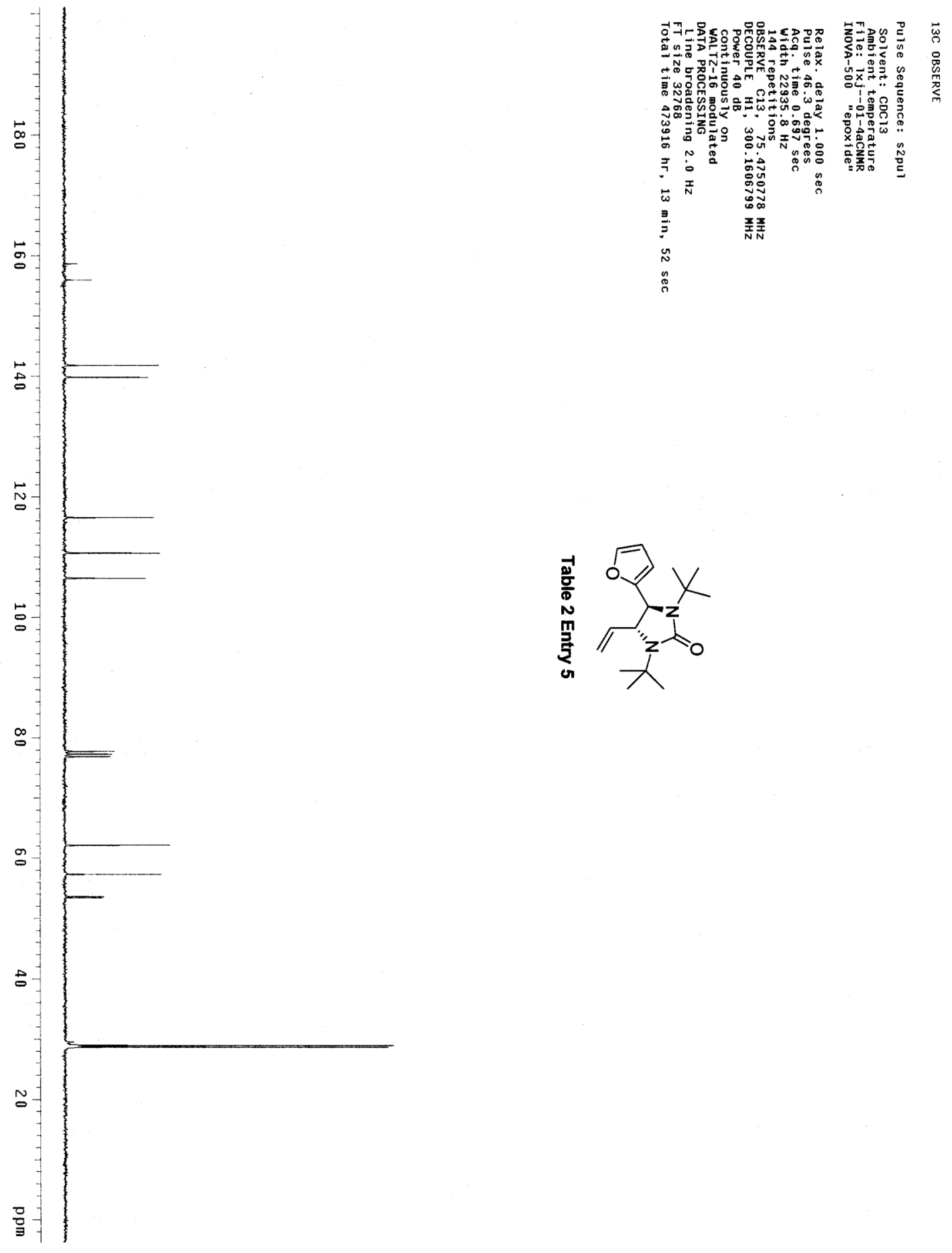

S-11 


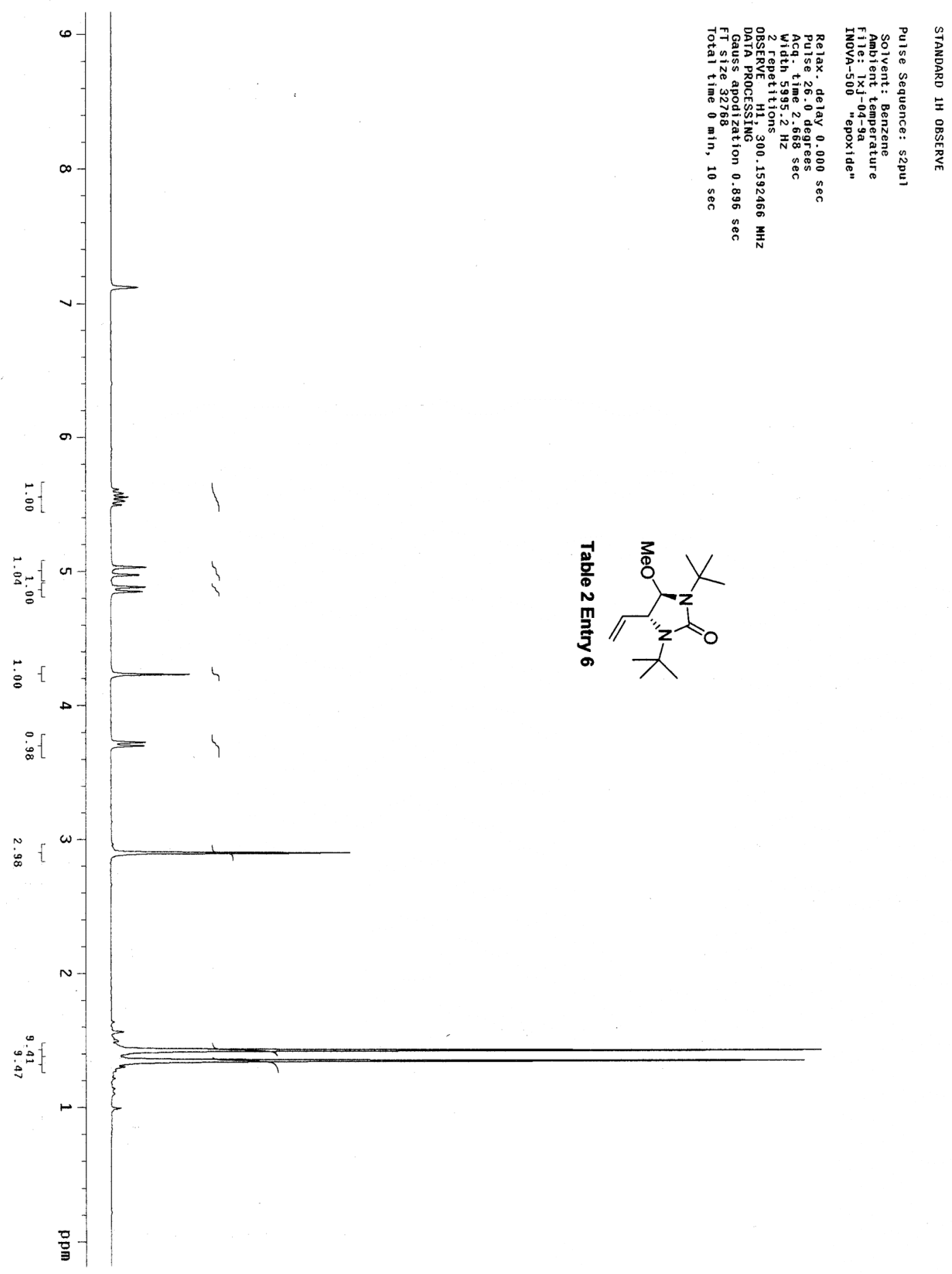



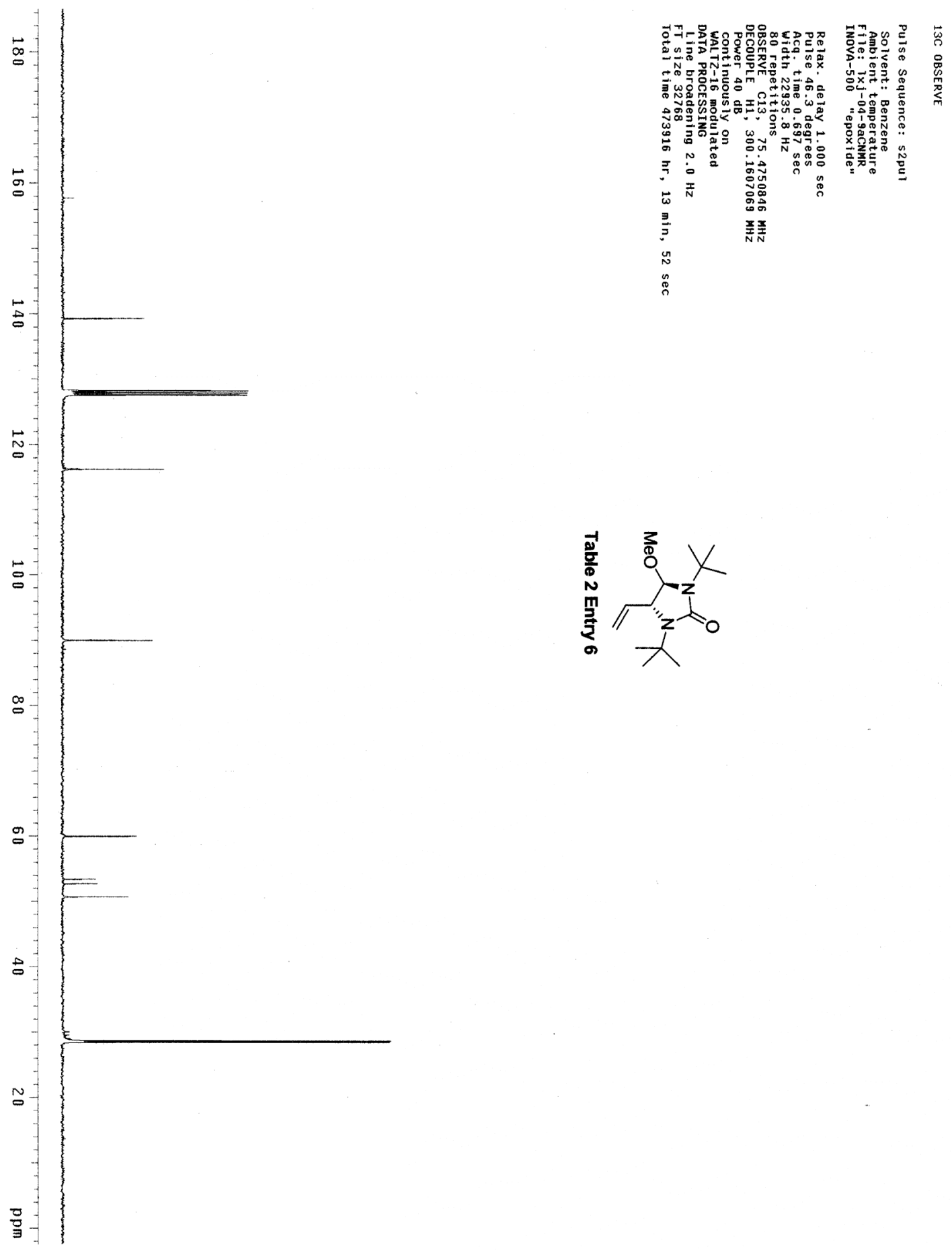

S-13 


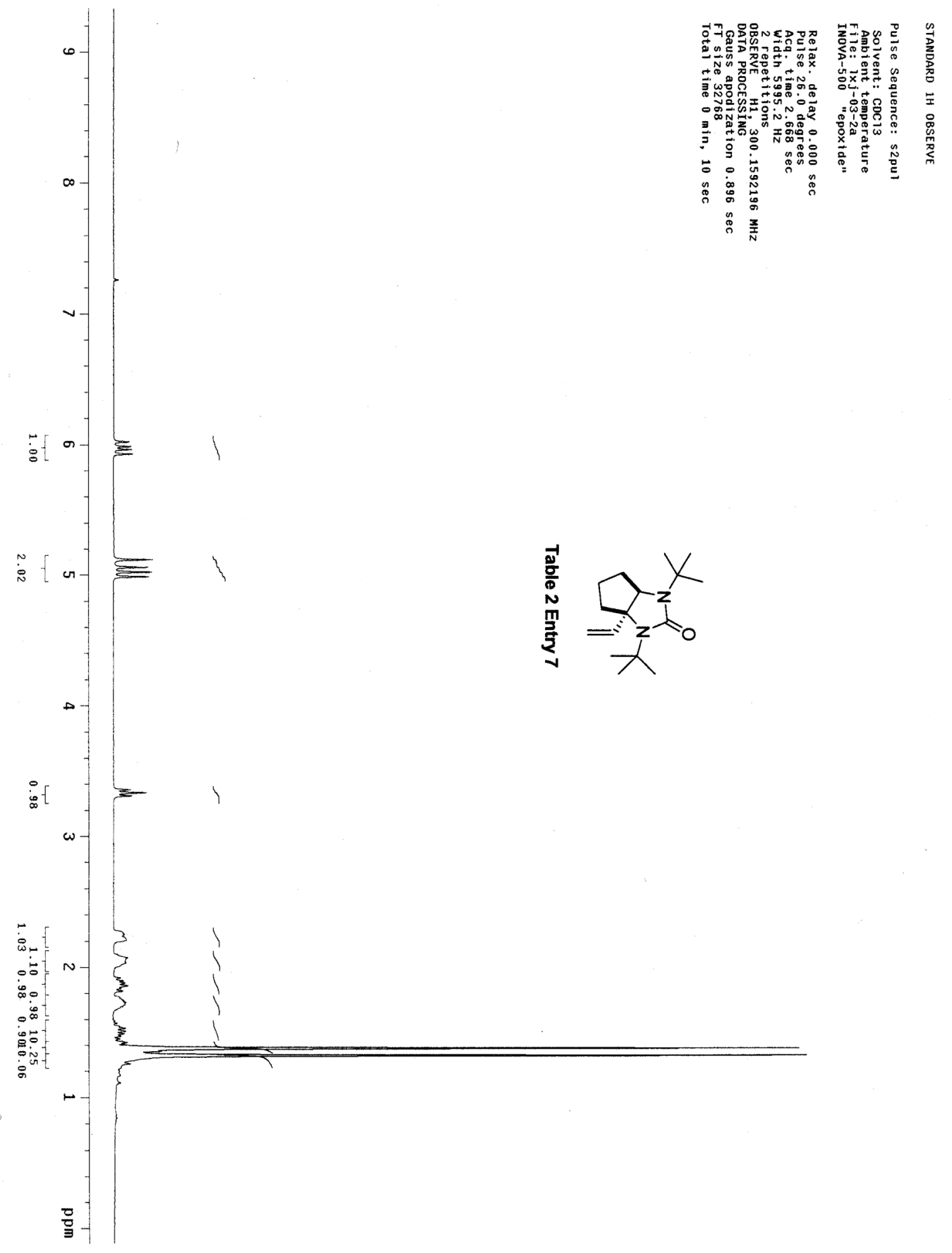




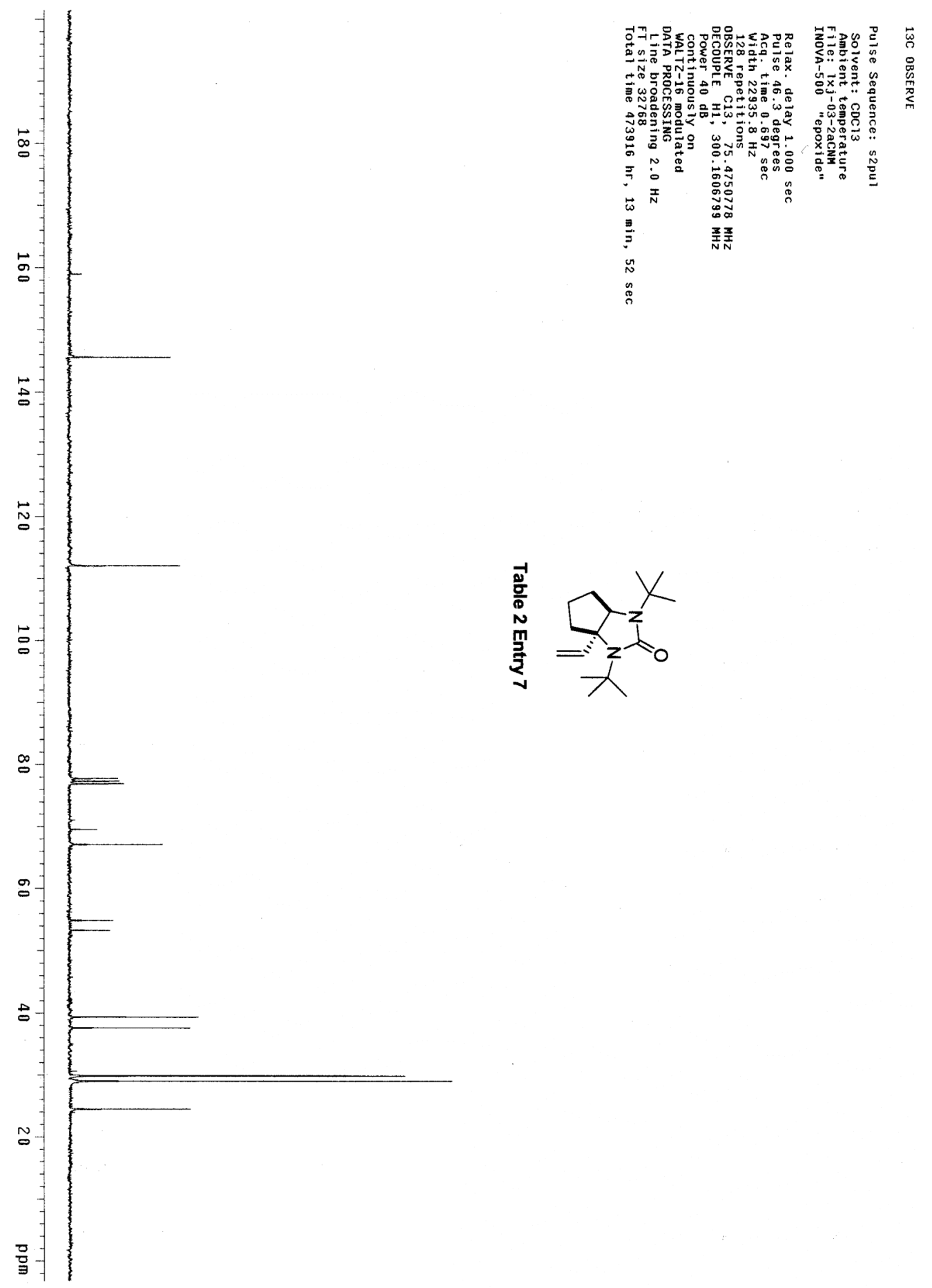

S-15 


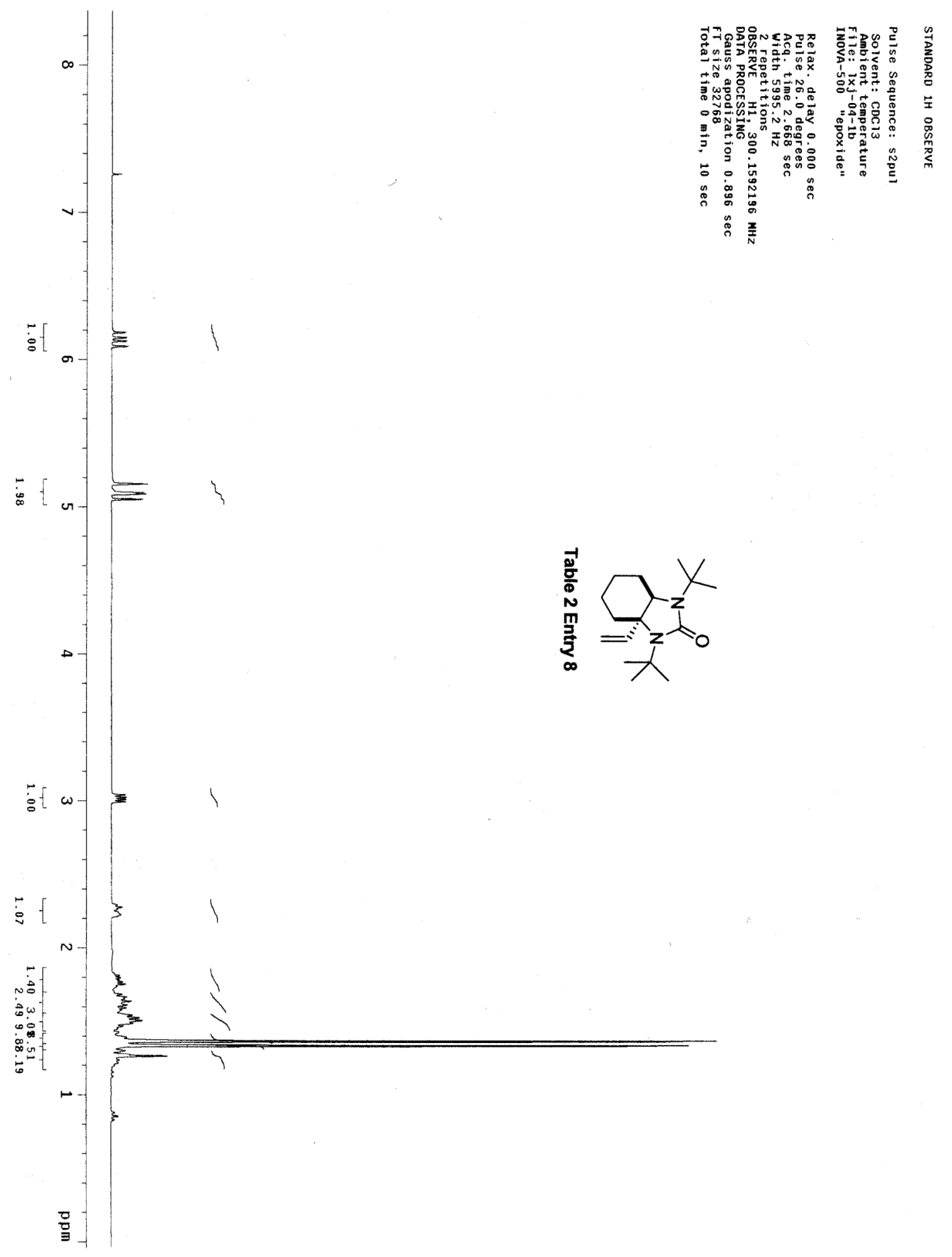

S-16 

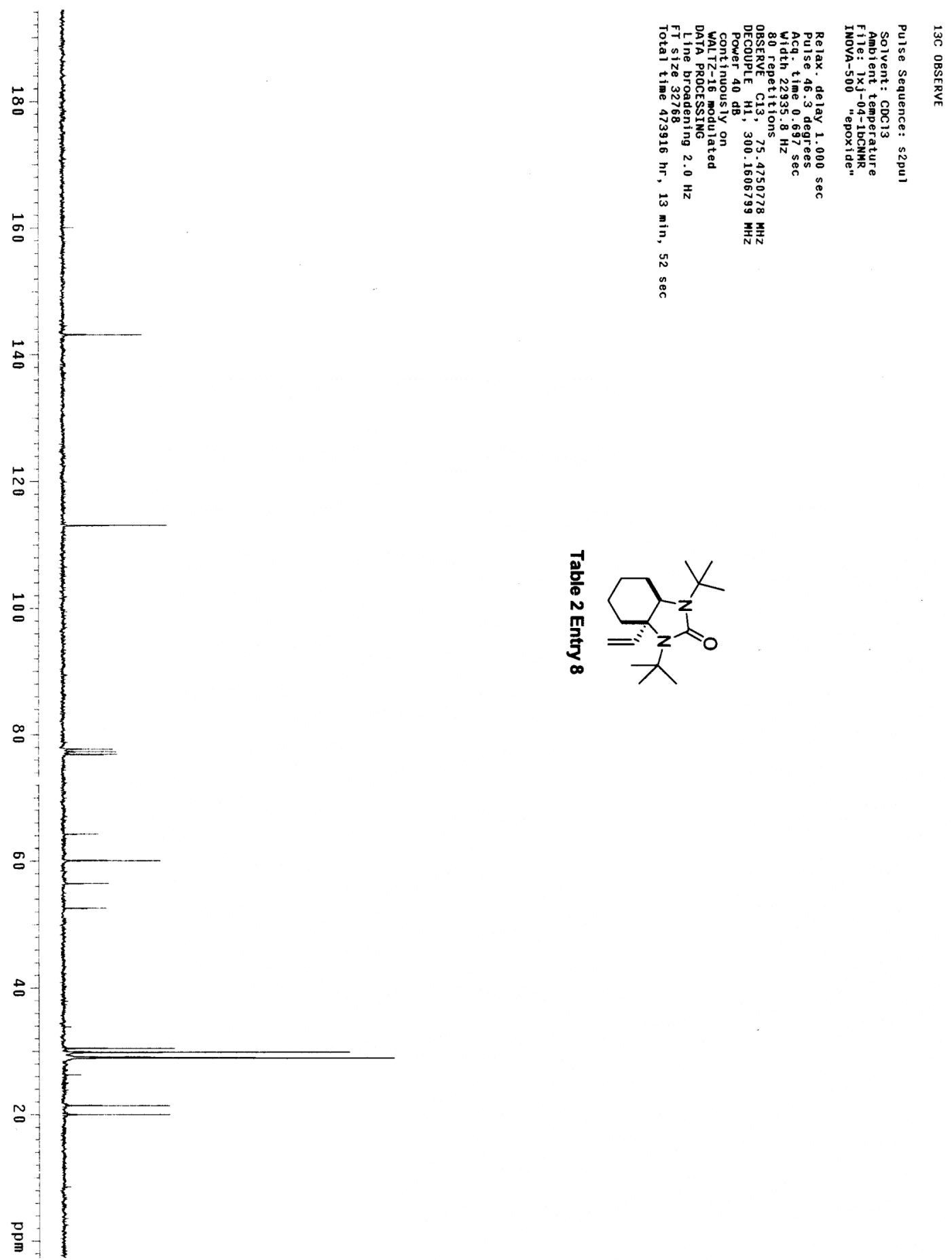


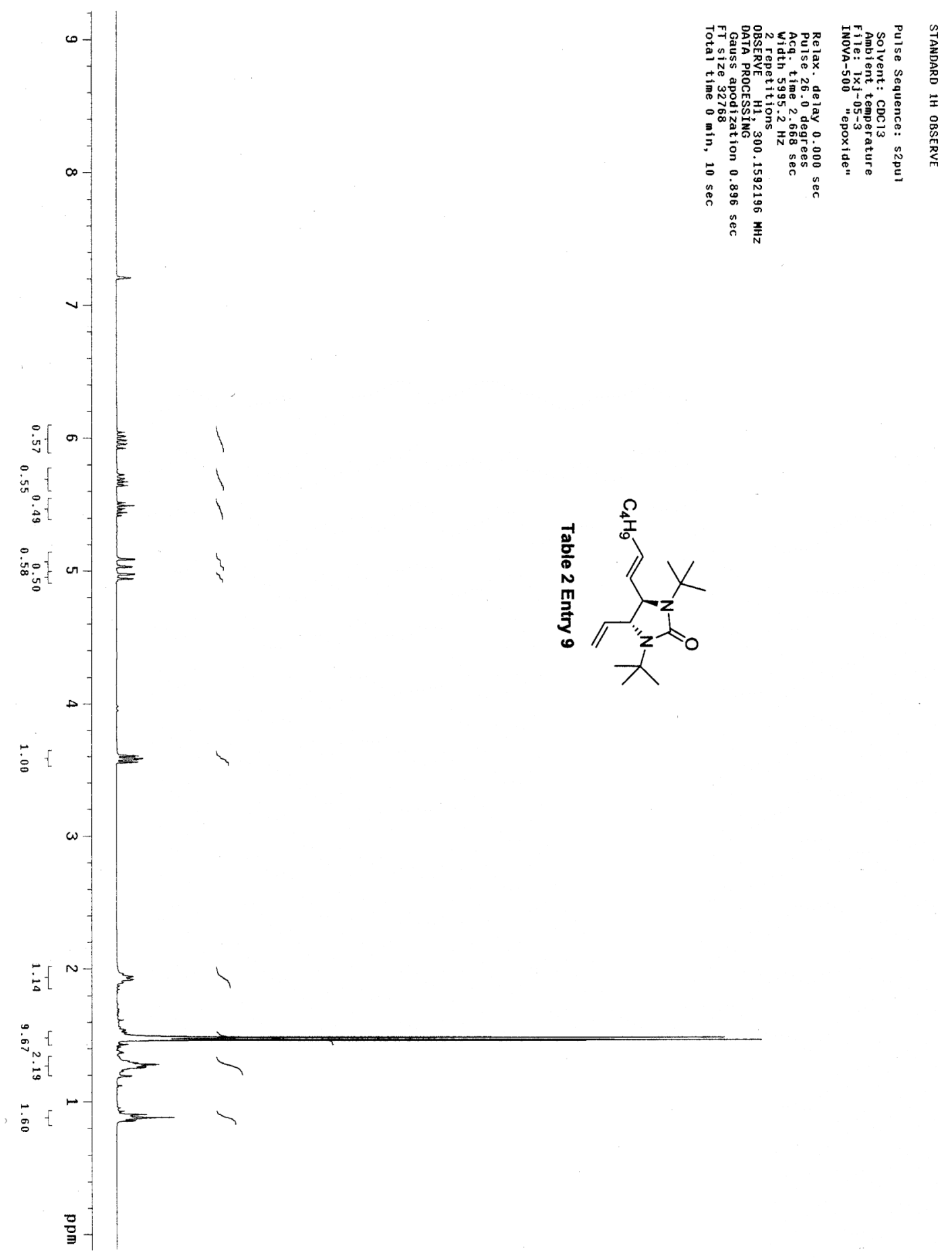



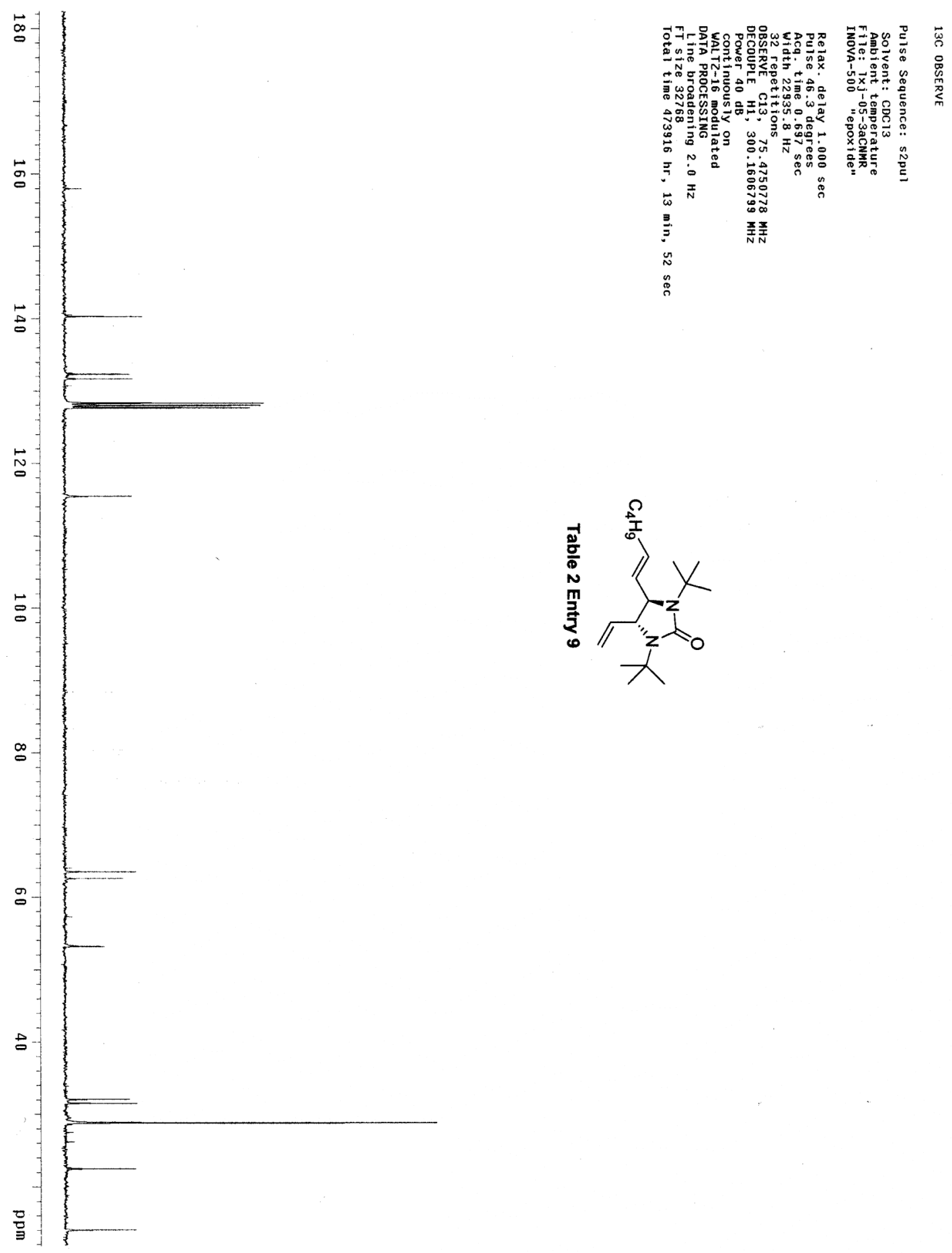

S-19 


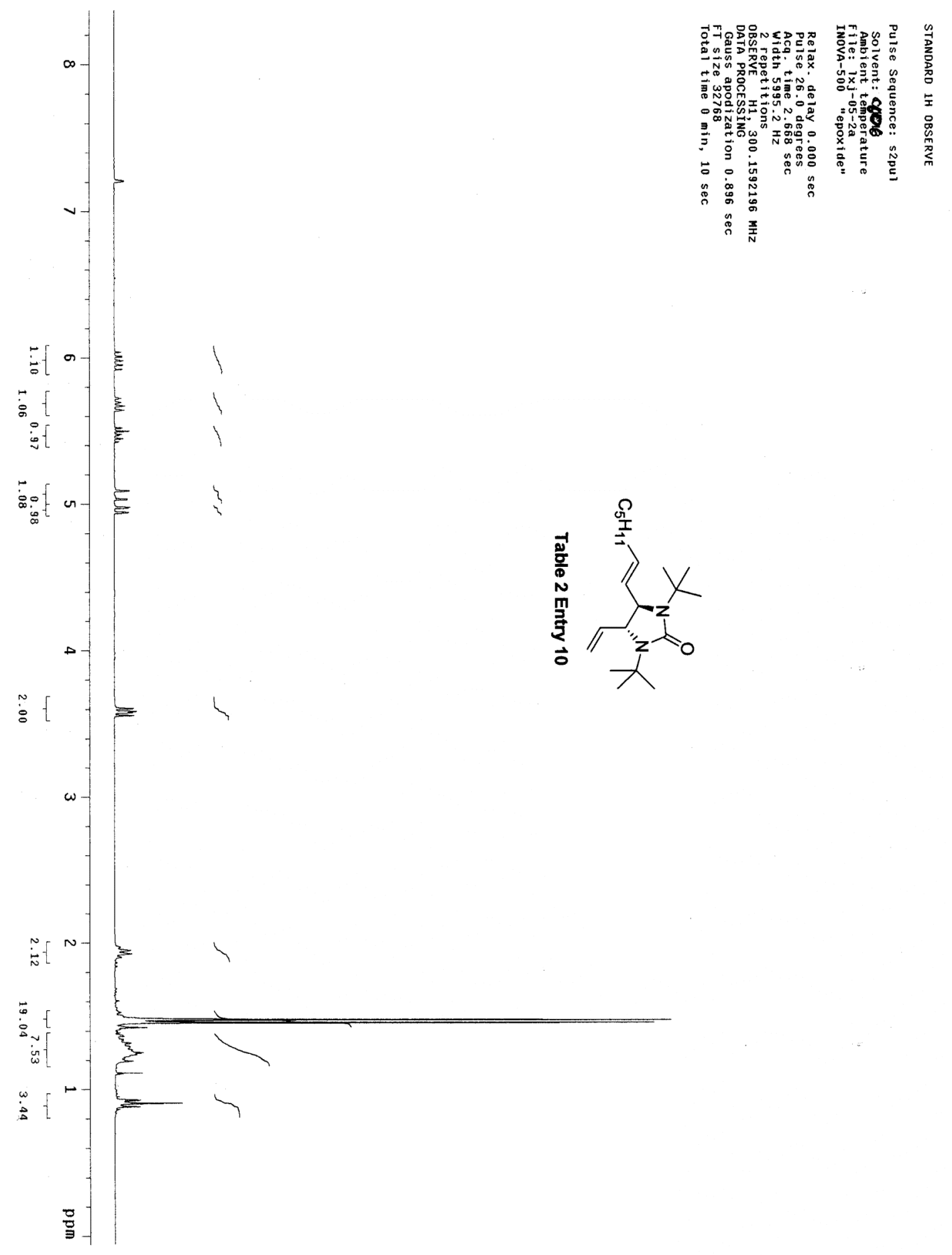



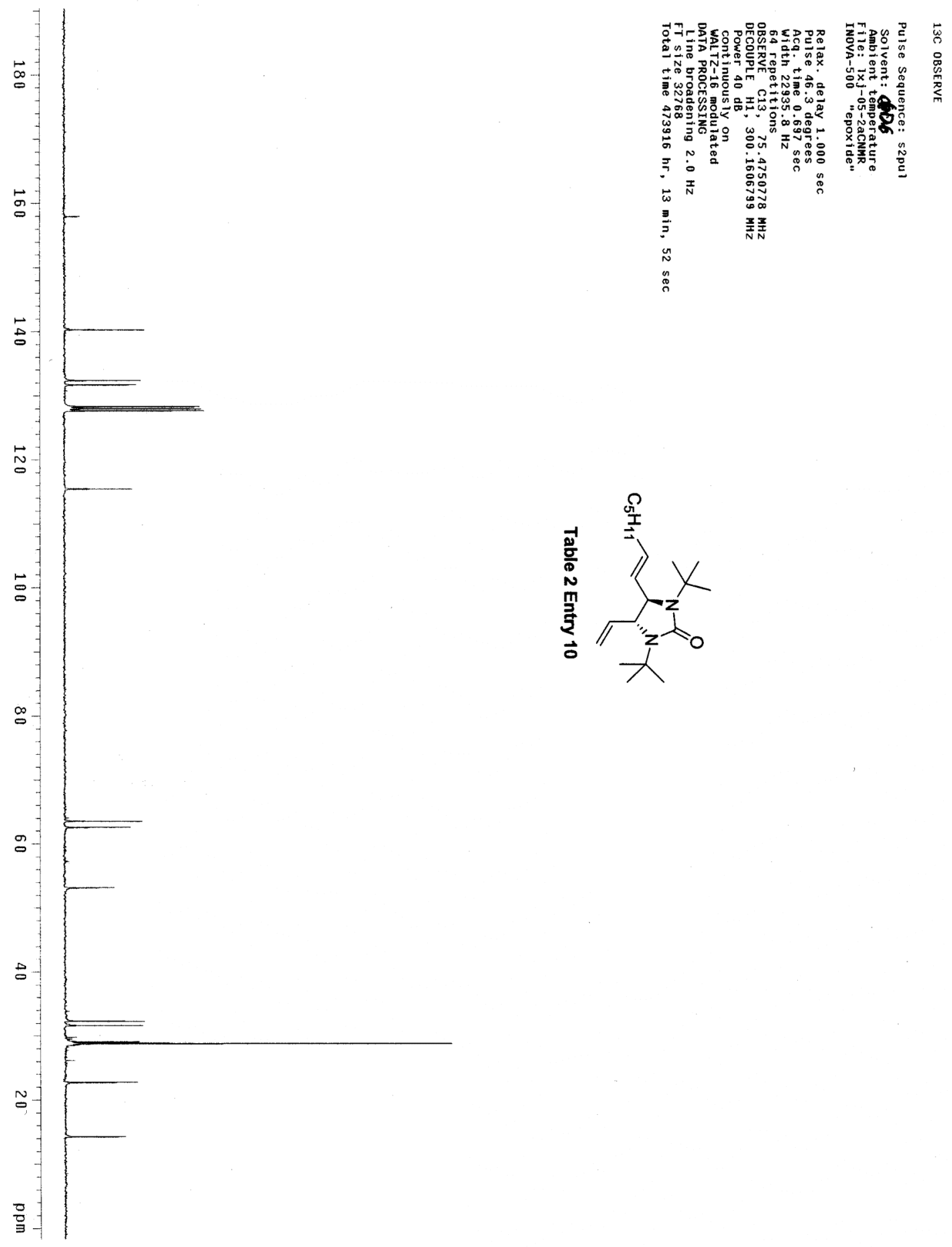

S-21 